\title{
System Approach for Cosmology: a Version of a High-Potential Philosophical Research
}

\author{
Vadim M. Rozin \\ Doctor of Philosophical Sciences, Professor, Institute of Philosophy of the Russian Academy \\ of Sciences (Moscow, Russia) \\ E-mail: rozinvm@gmail.com \\ https://orcid.org/0000-0002-4025-2734
}

\begin{abstract}
The author invokes issues (integrity of the Universe, epistemological status of its nature, system approach specifics) prompting to discuss once again the nature of the system approach in cosmology. For this purpose, he reviews the genesis of the system approach. The author considers Plato's representations concerning synthesis of many knowledge and introduction of the concept "system" in Condillac's and Kant's works. The opposition identified by them - a system is an organized scientific knowledge and a system as an object of this knowledge - may be found later in many system concepts. However George Shchedrovitsky additionally claims and shows that a system approach has to be specific to the developed subject domain. Therefore, in particular, when creating a system approach for a methodology, he interprets it as a section of methodology, and builds the latter upon this approach. Besides, Shchedrovitsky maintains that activity which was a subject matter in methodology acts as an intermediary between the methodology and the "system language". The author assumes that there is good reason for creating intermediaries in all similar cases. Agreeing with the division of the history of cosmology into two stages: "prescientific" (mythological and philosophical) and scientific proper, the author suggests calling them "protocosmology" and cosmology proper, claiming that in the first case the whole - Space, Universe - were set by means of mythological or philosophical schemes. The author explains his understanding of the concept of "scheme" and particularities of mythological and philosophical schemes of the Universe. Unlike with protocosmology, in cosmological doctrines Universe models are created on the basis of natural science schemes. But outside natural sciences - in philosophy and human sciences - philosophical schemes still contest these models. Proceeding from Vadim Kazyutinsky's works, the author asserts that in terms of key parameters Cosmology has to be referred to a humanitarian scientific discipline, and its object cannot be described within one scientific discipline; that "the cosmological reality" is a multi-level one, and each level is characterised by its own patterns which shall be described by different cosmological theories. Based on the above considerations, the author concludes that the system approach has to differ significantly from classical and synergetic approaches.
\end{abstract}

Keywords: system, approach, cosmology, protocosmology, methodology, discipline, Universe, scheme, model, doctrine, theory, reality, knowledge

Received: June 16, 2019; accepted: July 10, 2019

Future Human Image, Volume 12, 2019: 64-75.

https://doi.org/10.29202/fhi/12/5

(C) Rozin, Vadim M., 2019 
Expressions "Solar system" or "Universe system" may mislead and make an impression that the system approach has been already adopted in cosmology for a long time and is being implemented. But it is not so, such expressions are no more than metaphors. For example, "integrity" without which a system discourse cannot be realised, with respect to the Universe, as we know, is a complicated issue. "The most amazing consequence of nonstationarity," the academician Vitaliy Ginzburg writes, "is undoubtfully, the existence of "the beginning" or "the end", respectively, for expansion or compression. For common sense, it is difficult to reconcile with such a conclusion. However, we know well that "common sense" and development of science came into conflict more than once. Suffice it to recall disputes on sphericity of the Earth and on heliocentric system. It should be noted that criticism of heliocentric ideas was not at all limited to references to the Scriptus and church doctrines, but was also conducted from certain physical or, if you prefer, empirical positions. "Common sense" betrayed as well the English philosopher Francis Bacon. In 1622 he qualified Copernicus's theory "as speculation of a person who does not care of what fiction he brings into the nature, provided this lines up with his calculations". Today a famous physicist Hannes Alfvén criticizes "Big Bang" models (as quite often non-stationary cosmological models are called) from the same positions. I cannot but state that Alfvén's remarks both in terms of their contents, and especially in terms of their tone, produced a very painful impression on me. Claiming (without the slightest grounds and any arguments) that the observation data testifying in favour of existence of "Big Bang” allegedly disappeared, Alfvén writes further, "The less scientific proofs exist, the more fanatical the belief in this myth becomes. As you know, this cosmological theory represents the height of absurdity - it maintains that the whole Universe emerged at a certain moment like an exploded atomic bomb that measured (more or less) like a pin head. It seems that a huge advantage of "Big Bang" cosmology in actual intellectual environment is that it is an insult of common sense: credo quia absurdum (I trust because it is absurd)!" When scientists fight against astrological nonsenses out of "temples of science", it would be worth to recall that inside these walls still worse nonsense is sometimes cultivated ... The "community" of cosmologists and all astronomers in general (desultory deviations are not able to change this conclusion) cannot but admit the facts - obvious moving away of galaxies, their evolution, observation of relict radiation, etc. As a result, if disputes as to what extent is it possible to come nearer (in terms of extrapolation of available data) to the "beginning" (singularity) are admissible, the existence in the past of a dense hot phase, and thereby the "Big Bang" in the physical understanding of this term, does not raise doubts" [Ginzburg, 1982].

Nevertheless, counterarguments, and serious ones, are still adduced: and not only from the point of view of common sense, but also in respect of the extrapolation method - after all we judge the Universe by observing it from one, maybe vanishingly small, part - and from the point of view of other cosmological theories, which explain the same observations differently (see for example [Kazyutinsky, 1993]). Other doubts and issues concerning the Universe integrity and form see in [Marra, 2017; Panov, 2017; Stasishina, 2017, Kragh, 2014; Gil \& Alfonseca, 2014; Tavakol \& Gironi, 2017; Brandenberger \& Peter, 2017; Zinkernagel, 2014; Karpouzos, 2015; Ellisabc, 2014; Ackerman, 2017].

But there is one more problem: observations show that the system approach is not always the same, that is in different areas of knowledge the idea of systems is very different. For example, the organizational concept of a system in "Tectology" by Alexander Bogdanov [Rozin, 2018], is not similar to the "open system" concept of Ludwig von Bertalanffy [Vincenzi et al., 2016], and the latter, to the "four-layer" concept (a system as four structural layers: processes, 
functions, morphology and material) in the system-and-structural methodology concept of Georgy Shchedrovitsky. And what system concept is characteristic of cosmology? Should not it also be specific, catching the essence of problems and concreteness in this scientific and philosophical area?

I think, the answer such as "normal classical system concept used in natural sciences" will hardly suit us now, since, as I showed in the work "Regarding the problem of demarcation of natural and human sciences, as well as where shall we refer cosmology to", the question of a physical nature of the Universe is not at all simple and solved [Rozin, 2007; Nesteruk, 2011]. Besides, nowadays in the natural sciences there is no clarity with respect to the understanding and various types of the system approach [Panov, 2017; Book of Abstracts, 2016]. To understand, let us consider at first what is a system approach, and then we will return to the solution of the problem.

In the "New Philosophical Encyclopaedia" a system approach is characterized as follows: "an area of philosophy and methodology of science, special scientific knowledge and social practice based on research of objects as systems ... system approach is an interdisciplinary philosophical, methodological and scientific direction of researches ... is performs its heuristic functions, remaining a set of cognitive principles the main sense of which consists in proper orientation of specific researches" [Blauberg et al., 2001: 559-560]. Here, in my opinion, it is important to understand what does "interdisciplinary" mean and in what sense "heuristic"; these notions, really, grab something essential. Interestingly, some modern domains of philosophy and methodology of sciences relying on system approach such as synergetrics and knowledge engineering also consider themselves as interdisciplinary researches and heuristics. It is hardly by chance. Let us recall in the first place where did system ideas emerge for the first time.

They appeared at first in philosophy (Etienne de Condillac "Traité des systèmes", Immanuel Kant "Critique of Practical Reason"), then in chemistry, biology and sociology. But the specific reflection of the system approach is found only in the $20^{\text {th }}$ century.

Condillac understands under a system absolutely different thing from what we do. For him a system means principles and knowledge based thereon, describing the nature which are consciously created by a scientist. It seems that we have here a project of natural sciences. It is true, but Condillac's systems have one more function. Condillac understands as principles also provisions on which all other judgments of a certain system rely, and the prime causes (i.e. not knowledge any more, but the ontologic essence), and "the beginnings" (here Aristotle comes to mind), and even the "law" of the nature. Besides, according to him, the number of principles should be minimum, ideally only one ${ }^{1}$. It turns out that a system, according to Condillac, is both the nature taken in the natural science as an object, and an organized scientific knowledge of this object. The opposition identified here - a system is an organized scientific knowledge and a system as an object of this knowledge — may be found later in many system concepts.

It is also evident in Kant's works, but, on the one hand, Kant emphasises methodological interpretation of system notions (as procedures of thinking and work of a cognizer), and on the other - these notions are introduced for the first time. In fact, in the "Critique of Practical Reason" there is a special layer of terms and concepts which we refer today to a structural system thinking. So Kant widely uses such concepts as "functions" (functions of

1 "Deducing unconditional truth of the thesis about uniqueness of the primordium from the statement that "it is the clearest and rightest idea" (though it is obvious that it cannot be referred to "simple ideas" and feelings), Condillac demands recognition of absolute truth of this provision in spite of the fact that it is not capable to explain the facts and even contradicts the facts (about which we have "simple ideas" according to his theory, the most reliable)" [Condillac, 1980]. 
mind), "systems", "systematic unity", "the whole", "analysis and synthesis", "interrelations", "conditionality".

"Considering all our rational knowledge in all their volume," Kant writes, "we find that what the reason absolutely especially possesses and what it aims to implement, is systematicity of knowledge, that is interrelations of knowledge according to one principle. This unity of reason always assumes an idea, namely an idea about a knowledge form as the whole which precedes a certain knowledge of parts and comprises conditions for a priori place of any part and its relation to other parts" [Kant, 1964: 353-354] (the italicizing is ours - V.R.).

Kant's thought and reasoning move simultaneously in two planes: the plane of ideas about the reason (this is the whole, all parts and bodies of which have a certain purpose and are interconnected) and the plane of units (knowledge, concepts, categories, ideas, principles, etc.) from which Kant creates a building of Practical Reason. Each unit of the second plane has its reflection on the first one, thus allowing to attribute it new characteristics providing for the required organization of all structural units. It is structural-and-system conceptions that make it possible to make such a reflection and to characterize in a new way (systemically) all structural units. This, in particular, explains why Kant emphasizes persistently the advantage of synthesis as against analysis, as well as the importance of a set for the whole (unity):

"Our conceptions should be already given prior to any analysis, and no one concept can in terms of contents arise analytically. Synthesis of a diverse object (be it given empirically or a priori) generates first of all knowledge which originally can be yet rough and not clear and therefore needs analysis; nevertheless this is synthesis that actually makes knowledge of various elements and integrates them in a certain contents" [Kant, 1964: 173]. And here are two more statements. "Hence one can see that when drawing conclusions, the reason aims at reducing huge variety of knowledge to the smallest number of principles (general conditions) and reaching thereby their highest unity... the reason is related only to the application of the mind, and not because the mind comprises the basis of possible experience, but to assign it the direction for achieving such unity about which the mind has no idea and which consists in uniting all actions of the mind with respect to each subject in an absolute whole" [Kant, 1964: 344, 358].

What did Kant need the concept of the system for? Approximately for the same purpose, as Plato needed it in his "Symposium" when he understood that there are several definitions of love rather than one (love, according to Plato, is a search of one's half and an aspiration to integrity, this is an incubation of such spiritual offsprings as beauty, welfare and immortality, love is not god and not a man, but a genius, at last, this is a harmony diffused in the nature). Plato understood that if one fails to coordinate among themselves these different definitions of love, the knowledge received about love will be contradictory. In "Phaedrus" Plato solves the task of synthesis of different definitions (or as George Shchedrovitsky writes, he task of "configuring many knowledges") by referencing them to a single idea: “... it is the ability, by embracing everything by a general view, to trace to a uniform idea things that are discretely dispersed everywhere, giving a definition to each of them, to make clear the subject of the edification. We did the same a while ago, speaking about Eros: at first we defined what is it, and then, for better or worse, began to reason; therefore our reasoning became clear and did not contradict itself" [Plato, 1993: 176]. Plato calls such reflections dialectics. "I, Phaedrus," says Socrates, "am also a worshiper of such distinguishing and generalization — this helps me to reason and think. And if I notice in another a natural ability to embrace the ensemble and the multiple, I follow him "as god". Am I right or not treating those who can do it, only god knows, and I call them dialecticians" [Plato, 1993: 176]. 
Emphasizing in "Parmenida" a coherence of the ensemble and the multiple, speaking in the seventh letter about "mutual check — of a name by definitions, and of visible images, by feelings - and, what is more, if it is made in the form of a benevolent research, by means of good-minded questions and answers", Plato pays our attention to that particularity of this work which may be understood presently using a system approach.

Kant had a much more difficult task: he had to understand how to synthesize and configure such complex notions as "transcendental objects", "experience", "phenomena", "a priori basic foundations", "schemes of thinking", "mind", "reason" and a lot of other subjects. (Today, we would say that these notions belong to different subjects, and Kantian discourse is an interdisciplinary one). Kant solves this problem by creating — in a draft form as yet - a system approach and language (system concepts). Here again we see an opposition, but not an opposition of a scientific knowledge of the nature and the object of this knowledge, but of system thinking procedures (proceeding from the whole, adhering to the priority of synthesis over analysis, considering the whole, functions, links, etc.), and ontologic system conceptions (system, unity, connectivity and connections, functions, etc.). What is the role of ontologic system conceptions? First, they include knowledge that is obtained within the framework of a system discourse. Secondly, these conceptions give sense to system thinking procedures, for example, conceptions of interrelation force a philosopher or a scientist to reveal compositions of elements, to look for their interdependence, to take into account conditionality, etc.

It is worth paying attention to the role of the concept "whole" in a system discourse. According to Plato, the whole is set, on the one hand, by definitions of love (love as an ideal object), and on the other hand, by a subject considered by Plato (love as a life phenomenon). According to Kant, the whole is Reason with its components ("transcendental objects", "experience", "phenomena", "a priori basic foundations", "schemes of thinking", "mind", etc.) — all this is defined and constructed as ideal objects — but the whole is not reduced only to these ideal objects, it is perceived by Kant also phenomenologically, as a special subject. In other words, the system probably is always set in two ways: at a theoretical level (creation of ideal objects, receiving theoretical knowledge) and at a phenomenological level (in this case we perceive love or reason, or nature, or Universe within the framework of understanding more widely — of our life).

In connection with the last note the following question arises: shall the notion of a system include also specific concreteness, or, speaking differently, shall system approaches differ in different areas of knowledge and cognition? The answer is obvious: if the whole cannot be reduced to the respective ideal objects of the system, but is also perceived phenomenologically, then the notion of a system shall be weighted subject-wise. It has to grab particularities of a certain field of knowledge, a certain subject domain (biology, technical knowledge, law or, say, cosmology).

Perhaps, the first to find this solution was my teacher, George Shchedrovitsky. He faced two interconnected tasks - creation of the theory of activity and general methodology. In principle, both the transition from the subject point of view to methodological one and new synthesis of "reflexive contents" (approaches, concepts, situations in a subject, ideals of knowledge, reflection, etc.) making the main thing in methodological work assume analysis of these realities. But if Shchedrovitsky went this way, first, he would hardly solve problems he was concerned with in foreseeable terms, and secondly, he would get under a fire of criticism from other researchers of these realities. Here is what he writes, for example, about reflection, when discussing this issue. 
"Representations accumulated during the previous development of philosophy connect reflection, first, with processes of production of new meanings, secondly, with processes of objectivation of meanings in the form of knowledge, subjects and objects of activity, thirdly, with specific functioning of a) knowledge, b) subjects and c) objects in practical activities. And, probably, there is more to come. But even this is already too much to try to present everything directly in the form of a mechanism or a formal rule for designing and expanding schemes. Therefore we shall try to reduce somehow all these moments to simpler relations and mechanisms in order to deduce them from the latters and thus to organize everything in a uniform system" [Shchedrovitsky, 1995: 273].

In other words, Shchedrovitsky decided not to analyze reflexive realities (in this case knowledge, subjects, objects and their functioning, as well as mechanisms of production of new meanings), but to redefine and connect them in a new, more simple and constructive language. What is this language? The language of system approach (system-and-structural language) within the framework of which the activity is described now. "Initial fundamental representation: activity — system", wrote Shchedrovitsky in his work in 1975 [Shchedrovitsky, 1995: 241].

At the same time, to validate this step, he claims that system approach is only a variation of methodological work. "The area of existence of truly system problems and system objects," Shchedrovitsky writes, "it is the area of methodology" [Shchedrovitsky, 1995: 81]. "System approach in the present sociocultural situation can be created and will be effective only if it is included in a more general and wider task of creation and development of means of methodological thinking and methodological work" [Shchedrovitsky, 1995: 114]. "We may have", Shchedrovitsky writes, "only two strategies: 1) to "get down to business" immediately and to start designing system-and-structural representations, not knowing how to do it and what we have to get as a result, or 2) to design and create such an organization, or 'activity machine' which in the course of functioning would start processing modern system-andstructural representations in a harmonious and consistent system of system views and system elaborations... the design of the 'machine' itself guarantees that it will be methodological representations" [Shchedrovitsky, 1995: 109-110].

What is important for us, is not what Shchedrovitsky managed to construct as a result of such formulation of the question (by the way, a variation of system approach for the methodology of the Moscow Methodological Circle (MMC) was created [Rozin, 2019]), but how Shchedrovitsky resolves the issue of relation of system approach with objectness. The decision is unambiguous - system approach shall be specific for its subject domain ${ }^{2}$, in particular, Shchedrovitsky claims that system and methodological approaches shall be complementary, and developed together. Thus it became clear that activity which was the subject of development and studying in MMC, mediates between the subject (methodology in Shchedrovitsky's option) and "system language" ("a system of concepts and ontologic representations" which were used for synthesis and configuring many knowledge elements and subjects). If as a subject of knowledge is a complex phenomenon presented to the researcher in the form of many knowledges and subjects, the creation of the concept and theory of this phenomenon assumes the use of system language and discourse within the framework

${ }^{2}$ Unfortunately, at the conceptual level there is no understanding of this relation in scientific community though in practice many researchers relate system approaches offered by them with certain subject domains [Maracha, 2018; Flood, Romm, 2018; Mobus, 2015, 2017; Morecroft, 2015; Rousseau et al., 2016]. 
of which the synthesis and configuring are performed. Perhaps, Igor Blauberg, Eric Yudin, Vadim Sadovsky, meant this speaking about interdisciplinarity and heuristicity of the system approach.

A thought comes to mind that it is not by chance that in all such cases it is necessary to create intermediaries [Rousseau et al., 2016]. Is not, for example, in Kant such an intermediary the notion of Reason, in semiotics, the notion of communication, in Michael Bakhtin's theory the notion of dialogue, and in Alexander Bogdanov's conception, the notion of organization? Possibly, intermediaries make it possible to pass from characteristics of concreteness to very different characteristics of system language.

Let us return to cosmology now. Most researchers are unanimous in distinguishing two stages of its development: so to speak, "prescientific" (meaning natural sciences), mythological and philosophical, and scientific proper, up to modern concepts and theories. According to these stages it is possible to speak about "protocosmology" and cosmology proper. If we are talking about protocosmology, the whole — Space, Universe - was defined by means of mythological or philosophical schemes. Two words about schemes.

Not models, not ideal objects of science, but exactly schemes. Schemes, according to Shchedrovitsky, are the main tools of methodology. I tried to distinguish schemes and models in my work "Introduction to schemology: Schemes in philosophy, culture, science, design" [Rozin, 2011]. If modelling assumes preliminary assignment in some form or other of an object modelled, as well as a possibility to refer knowledge received using a model to this object, claiming for the given context equivalence of the model and the object modelled, the scheme has no such restrictions, it defines by itself the object which it describes. The scheme only allows to understand and to act in a certain way. For example, if we use the subway scheme to determine the length of a travel (by counting and comparing the number of stations along different routes), in this case this is a model. But if the subway scheme is used by a passenger who found himself for the first time in the subway, say, to understand the environment he got into, and what he can do there in general (to change lines, to enter stations and to leave them, to follow any route), this is a scheme. Schemes are created to solve "a problem situation", they set a new reality and the object therein for the first time. Schemes allow to understand what is happening, and to act accordingly. Judging by researches of Alexey Losev, schemes were introduced and discussed for the first time by Plato, then they are discussed by Immanuel Kant, then by participants of the Moscow Methodological Circle from which originated as well your obedient servant and, partly, Alexander Popov.

Comparing ideas of schemes according to Plato and Shchedrovitsky, it is possible to identify two first characteristics of the notion "scheme": 1) schemes are created by a man as a preliminary condition of knowledge, they allow to plan the main characteristics of the object of study, bring us to it, but only bring, this object is actually studied in the field of knowledge, however, often only on schemes we can tap into essential characteristics of the object which we investigate, and 2) schemes create conditions for activity (practical or cognitive). The third characteristic of the notion "scheme" is that they perform several functions: they help to understand the events, organize and reorganize the man's activity, accumulate meanings which were not interconnected in any way before, facilitate identification of a new reality.

Schemes appear (are invented) in situations presenting problems; this is by means of schemes that these problems are solved and a new object (reality) is formed. A prerequisite of development of schemes is defining, that is substituting in the language one notions for others. In this sense the scheme seems to be a kind of signs, however, the main thing in schemes is not 
a possibility to act instead of a designated object, but to solve problems, to set a new vision and to organize activity. If we place emphasis on the latter, then the sign function of a scheme acts only as a condition of schematization. Then schemes cannot be put in one row with signs. In this case schemes are an independent reality, rather than an epistemological entity, just about what Kant wrote.

What were particularities of mythological and philosophical schemes of the Universe? They had to explain phenomena observed by a man on the Earth and in the Sky within the boundaries either of the idea of so-called "Big Home" where all people, animals and their souls live (mythological vision) or the idea of the House (World) created by gods (religious vision) or the idea of the World (space, nature), which has always existed, supported by the thought of Reason/God (Aristotle). It is clear that here the whole was defined not by a natural-science thought, but by problems and ways of solution of these problems by separate communities or, in antiquity, by individuals behind whom also some communities stood. Since synthesis and configuring of different knowledge about observed phenomena were carried out using schemes, the knowledge obtained differed drastically from the natural-science knowledge. For example, mythological and religious knowledge could be inconsistent, but on the other hand they offered an explanation and allowed to act. Antique philosophical knowledge of the Universe was consistent, but also received through schemes [Rozin, 2017: 6, 55].

Does the foregoing mean that the natural-science knowledge of the Universe which replaced mythological and philosophical knowledge, was created without schemes? It may be demonstrated that it is not so, only in this case on the basis of initial schemes models were created $^{3}$. "Prediction of discovery of Neptune," Vadim Kazyutinsky writes, "was the triumph of the theory of gravitation. Based on the Newtonian mechanics, the cosmogony (hypothesis by Georges Buffon, Kant, Pierre Laplace) received new impulses ... The research program following traditions of Kant, Laplace, Jeans was called classical one. At first it was developed within the framework of Newtonian cosmogony, then fundamental laws of nonclassical physics ... Star formation processes occurring according to the classical concept through condensation of diffused substance are almost directly observed by means of new astronomical devices now ... Some types of objects unknown to astronomy have been found: active galaxy nuclei, quasars, cosmic background radiation, pulsars, burst x-ray and gamma radiation sources, other planetary systems the existence of which was predicted by J. Bruno ... The point of view of supporters of the classical paradigm was summed up by Joseph Shklovsky in 1979 as follows: "Many things are not clear yet and have to be learned, but the 'master plan', the interrelation of objects, and, above all, the history of development (of the Universe), are understood and passed into the category of absolute truth"'" [Kazyutinsky, 1993: 26, 27, 30].

In case of a natural-science approach the whole of the Universe is set by the laws of nature, then on their basis hypotheses about organization and borders of the Universe are made, observations are conducted, processes running in the Universe and parameters of space objects are calculated. There is also a clear foundation for the system approach: a variety of knowledge and subjects of study and observation can be synthesized and configured on the basis of classical natural-science and synergetic system representations [Mobus \& Kalton, 2014; Wilby et al., 2014].

\footnotetext{
${ }^{3}$ In "Discourses" Galilei showed how on the basis of mathematical schemes create models describing natural processes, and Christian Huygens, relying on Galilei's works, created the first model of engineering activity (see in more detail [Rozin, 2011: 192-200]). Mathematical scheme $\rightarrow$ experiment $\rightarrow$ mathematical model $\rightarrow$ engineering activity $\rightarrow$ real mechanism (machine).
} 
However natural-science approach in cosmology is contested by others, which are based not on schemes and models of natural sciences, but on schemes of philosophy and human sciences [Bazaluk \& Kharchenko, 2018]. You may ask why? Because, first, the natural-science explanation faced a number of significant challenges. Secondly, in my opinion, because the knowledge of the Universe is ethically and existentially loaded (after all the Universe is our home, but what, interestingly, prospects open before the mankind in a house built by astrophysics? According to them, sooner or later, all of us have to disappear either as a result of falling of an asteroid, or compression or dispersal of the Universe, or any other natural process).

"Doubts," Kazyutinsky writes, "are generated by three circumstances. First, modern evolutionary theories in astrophysics have not yet a sufficient amount of predictions confirmed on their basis, i.e. they not quite satisfy the substantiality criterion accepted in the (natural. V.R.) science. On the contrary, some predictions do not come true (for example, the flow of solar neutrinos turned to be significantly less than the one predicted by the theory). Secondly, despite almost semicentennial researches of active processes in galaxies, many of them have no quite reliable explanation yet. As a matter of fact, we still do not know what is happening in galactic kerns. Thirdly, numerous and very sophisticated attempts to resolve the "paradox of mass" have not been crowned with success so far. According to modern representations, accumulation of galaxies shall be stationary. But in this case we have to admit that $95-98 \%$ of the Universe substance mass are in an invisible state (a "hidden mass"). All attempts to understand the physical nature of hidden masses "hung in mid-air" so far [Kazyutinsky, 1993: 31].

Especially intolerant, as we know, is the "singularity problem", according to which, if moving back to the beginning of dispersal of galaxies, we shall come to the zero point where many physical parameters (the mass of substance, radiuses of particles, etc.) take on infinite or zero values, losing thereby their physical meaning. There is also such a fundamental question as what was there "prior to" singularity. Some researchers "prudently declared that currently there is no reasonable physical answer to this question yet" [Kazyutinsky, 1993: 34]. If it does not exist in physical reality, then, as I show, this problem can be resolved within the framework of human sciences. And how it is possible to interpret the answers given by many cosmologists: this question is senseless because time — as still Augustine believed — "had to appear together with the Universe" [Kazyutinsky, 1993: 34]. By the way, in human sciences the choice of initial presumptions (in this case, the general relativity theory) and interpretation of phenomena observed, as well as of consequences resulting from the theory depend only on one thing — the identity of the scientist, his values and vision.

The case of criticism of the extrapolation principle on the basis of which the whole cosmology is being built is no less interesting. "Some cosmologists opposing the Friedmann tradition (especially, Edward Milne, Hermann Bondi, Thomas Gold) demonstrated a deeply negative attitude to the extrapolation method in cosmology". They were of opinion that "the Universe as a whole is a so unique object that its research on the basis of extrapolation is impossible in principle" [Kazyutinsky, 1993: 31].

As a result the conclusion which is drawn by V. Kazyutinsky does not surprise: "The offered interpretation of the Universe as a whole is in line with the idea of plurality of ontologic worlds ... The main idea of the author - that the concept of the Universe as a whole is in fact relative, instead of being a kind of a physical absolute established once and forever - came true" [Kazyutinsky, 1993: 13]. And your obedient servant took things a step further. Analyzing Kazyutinsky's works, I drew the following conclusion. 
Cosmology has to be in all respects classified as a scientific discipline of humanitarian type that does not exclude availability therein of various physical and other natural-science disciplines. The object of cosmology (similar to the objects of biology, cultural science, sociology) cannot be described within one scientific discipline. "The cosmological reality" is a multi-level one, and each level is characterised by its own patterns which shall be described by different cosmological theories. From the point of view of the philosophy of science, the Universe as an object of study of cosmology represents ideal objects of humanitarian theories which are created based on facts (astronomical observations and their interpretation), in the process of implementation of the cosmologists' values and approaches, carrying out a humanitarian discourse (for example, interpretation of astronomical observations as specific texts and Space activity), taking into account the humanitarian nature of the Universe (plurality of cosmological theories, anthropic principle, etc.) [Rozin, 2007].

Proceeding from our reflections about system approach, it is possible to assume that this approach for the second understanding of cosmology offered here has to differ significantly from classical and synergetic approaches. For example, the integrity of the Universe will be established in this case not only by the laws of the first nature, but also by problems facing representatives of philosophy and human sciences. Besides, this integrity will be conditioned by modern paradigms of philosophical, natural-science and humanitarian thinking. It is not unlikely that the understanding of this integrity will be also significantly influenced by collective dialogues of communities of the people of the Earth 'floating' in the space in the same boat.

\section{References}

Ackerman, Ari Hasdai. Crescas and Scholastic Philosophers on the Possible Existence of Multiple Simultaneous Worlds. Aleph, Vol. 17, No. 1 (2017), pp. 139-154. https://doi. org/10.2979/aleph.17.1.0139

Alasuutari, Pertti. The discursive construction of personality. Lieblich, Amia and Ruthellen Josselson (Eds.). The narrative study of lives, vol. 5. Sage, Thousand Oaks, CA, 1997: $1-20$.

Bazaluk, Oleg, and Larysa Kharchenko. The Philosophy of the Cosmos as the New Universal Philosophical Teaching about Being. Philosophy and Cosmology, Volume 21, 2018: 6-13. https://doi.org/10.29202/phil-cosm/21/1

Blauberg, Igor, Yudin, Eric, Sadovsky, Vadim. System approach. NFE. V.3. M, 2001., pp. 559-560.

Book of Abstracts. European Meetings on Cybernetics and Systems Research Vienna 2016. Editors by Stefan Blachfellner and Tess Marja Werner. 2016. https://emcsr.net/wpcontent/uploads/2016/12/emcsr-avantgarde-2016-Book-of-Abstracts.pdf

Brandenberger, Robert, and Patrick Peter. Bouncing Cosmologies: Progress and Problems. Foundations of Physics. June 2017, Volume 47, Issue 6, pp 797-850. https://doi. org/10.1007/s10701-016-0057-0

Condillac. Traité des systèmes. 1980. http://knigi.link/kondilyak/traktat-sistemah-traite-6781. $\mathrm{html}$

Ellisabc, Rayner. Studies in History and Philosophy of Science Part B: Studies in History and Philosophy of Modern Physics. Volume 46, Part A, May 2014, Pages 5-23. https://doi. org/10.1016/j.shpsb.2013.07.006. 
Flood, Robert, and Norma Romm. A Systemic Approach to Processes of Power in Learning Organizations: Part II - Triple Loop Learning and a Facilitative Intervention in the “500 Schools Project”. The Learning Organization, 25(4):260-272, December 2018. https://doi.org/10.1108/TLO-11-2017-0106

Gil, Francisco and Manuel Alfonseca. About the Infinite Repetition of Histories in Space. Theoria: An International Journal for Theory, History and Foundations of Science. Vol. 29, No. 3 (81) (September 2014), pp. 361-373. Published by: University of the Basque Country (UPV/EHU). https://www.jstor.org/stable/43612983

Ginzburg, Vitaly. What is the role of philosophy, astronomy and physics in the solution of the most urgent problem of cosmology — the choice of the Universe model consistent with the reality. Earth and Universe. 1981. No. 1. https://www.bestreferat.ru/referat-219926. html

Kant, Immanuel. Critique of Practical Reason. Collected works in 6 v. V. 3. Moscow, 1964.

Karpouzos, Alexsis. Cosmology Philosophy and Physics. Published by Think.Lab, Athens, Greece 2015. Pp. 1-58.

Kazyutinsky, Vadim. Traditions and revolution in modern astronomy. Doctoral thesis. Moscow, 1993.

Kragh, Helge. Naming the Big Bang. Historical Studies in the Natural Sciences, Vol. 44, No. 1 (Feb., 2014), pp. 3-36; Published by: University of California Press, https://doi. org/10.1525/hsns.2014.44.1.3

Maracha, Vyacheslav. System thinking and procedures of collective solution of problems. System analysis in economy - 2018: Collected works of the V Biennial International Scientific and Practical Conference (November 21-23, 2018) / edited by G. B. Kleyner, S.E. Shchepetova. — Moscow: Prometheus, 2018. — pp. 365-368.

Marra, Valerio. Understanding Our Only Universe. Philosophy and Cosmology, Volume 19, 2017

Mobus, George. A Systems Science Framework for Understanding the Nature of Governance. Proceedings of the $59^{\text {th }}$ Annual Meeting of the ISSS - 2015 Berlin, Germany, Vol 1, No 1, 2015. http://journals.isss.org/index.php/proceedings59th/article/download/2497/883

Mobus, George. A Framework for Understanding and Achieving Sustainability of Complex Systems: Framework for Sustainability of Complex Systems. Systems Research and Behavioral Science, Vol. 34 Issue: 5, 2017, pp. 544-552, https://doi.org/10.1002/ sres. 2482

Mobus, George, and Michael Kalton. Principles of Systems Science. Springer, 2014.

Morecroft, J. Strategic Modelling and Business Dynamics. A Feedback Systems Approach. John Wiley and Sons Ltd, Chichester, 2015.

Nesteruk, Alexei. Cosmology at the Crossroads of Natural and Human Sciences: is Demarcation Possible? Part 2. Explication. In. Journal of Siberian Federal University. Humanities \& Social Sciences 5 (2011 4) 644-666

Panov, Alexander. The Structure of Reality, or Where to Find the Final Theory? Philosophy and Cosmology, Volume 19, 2017: 74-94

Plato. Fedr. Collected works in 4 v. V.2. Moscow, 1993.

Rozin, Vadim. Regarding the problem of demarcation of natural and human sciences, as well as where shall we refer cosmology to. Epistemology \& Philosophy of Science. No. 1. 2007. 
Rozin, Vadim. Introduction to schemology: Schemes in philosophy, culture, science, design. Moscow: LIBROKOM, 2011.

Rozin, Vadim. Nature: The notion and the stages of development in the European culture. Moscow: LENAND, 2017.

Rozin, Vadim. The ideas of Bogdanov's "Tectology" in works of the architect Rosenberg (the first stages of formation of the methodology of design). Urbanistics. 2018. No. 3., pp. 162-170. https://doi.org/10.7256/2310-8673.2018.3.27899

Rozin, Vadim. Georgy Shchedrovitsky's Concept of Activite and Thought-Activity. In Philosophical thought in Russia in the second half of the twentieth century. BloomsburyAcademic, New York • London • Oxford • New Delhi • Sydney. 2019. Pp. 245-259.

Rousseau, D., Wilby, J., Billingham, J., Blachfellner, S. Manifesto for General Systems Transdisciplinarity. Systema 4(1), 2016. Special Issue - General Systems Transdisciplinarity, pp. 4-14, http://www.systema-journal.org/article/view/401

Shchedrovitsky, Georgy. Initial representations and categorial means of the theory of activity. Selected works. Moscow, 1995.

Shchedrovitsky, Georgy. System movement and outlooks of development of the system-andstructural methodology. Selected works. Moscow, 1995a.

Shchedrovitsky, Georgy. Principles and general scheme of methodological organization of system-and-structural researches and development. Selected works. Moscow, 1995b.

Stasishina, Yulia. Our world is not the only: the theory of parallel Universes. 2017. https:// sciencepop .ru/nash-mir-ne-edinstvennyj-teoriya-parallelnyh-vselennyh/

Tavakol, Reza, Gironi, Fabio. The Infinite Turn and Speculative Explanations in Cosmology, in Foundations of Science. December 2017, Volume 22, Issue 4, pp. 785-798. https:// doi.org/10.1007/s10699-016-9499-2

Vincenzi, Simone, Crivelli, Alain J., Stephan Munch, Stephan, Skaug, Hans J. and Mangel, Marc. Trade-Offs between Accuracy and Interpretability in Von Bertalanffy RandomEffects Models of Growth. Ecological Applications, vol. 26, no. 5, 2016, pp. 15351552 .

Wilby, J., Blachfellner, S., Hofkirchner, W. (eds.), (2014). Civilisation at the Crossroads. Response and Responsibility of the Systems Sciences, European Meetings on Cybernetics and Systems Research. Book of Abstracts. Bertalanffy Center for the Study of Systems Science, Vienna.

Zinkernagel, Henrik Philosophical aspects of modern cosmology. In Studies in History and Philosophy of Modern Physics 46 (Special Issue on Philosophy of Cosmology), 2014, pp. 1-4. 